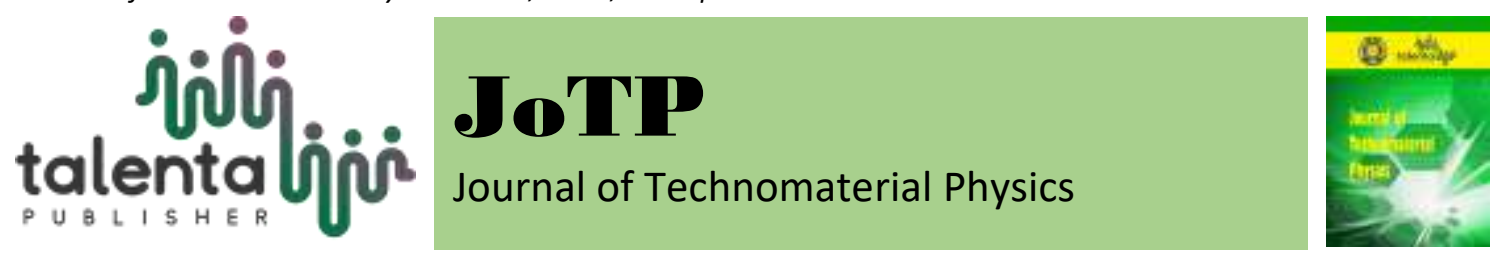

\title{
Preparation of Terminalia catappa Shell Based Activated Carbon by Microwave Assisted Chemical Activation
}

\author{
Awitdrus $^{I}$, Yaya Pradita ${ }^{2}$, Rakhmawati Farma ${ }^{3}$ and Iwantono ${ }^{4}$ \\ ${ }^{1,2.3,4}$ Department of Physics, Faculty of Mathematics and Natural Science, Universitas Riau, Pekanbaru \\ 28293, Indonesia
}

\begin{abstract}
Activated carbon was prepared from Terminalia catappa shells using microwave assisted $\mathrm{KOH}$ activation. The ratio of mass percentages of Terminalia catappa and $\mathrm{KOH}$ were $4: 1,4: 2$, and 4:3. Terminalia catappa based activated carbon was prepared by $\mathrm{KOH}$ activation at the room temperature for 24 hours and followed by microwave irradiation at the output power of 630 Watt for 20 minutes. The physical properties of activated carbon i.e. surface morphology, micro structure, and BET surface area were characterized by electron scanning microscope, $\mathrm{X}$-ray diffraction and $\mathrm{N}_{2}$ adsorption-desorption isotherm at $77 \mathrm{~K}$, respectively. The highest BET surface area was $312 \mathrm{~m}^{2} / \mathrm{g}$ with adsorption of activated carbon towards methylene blue by $84.4 \mathrm{mg} / \mathrm{g}$. The BET surface area was directly correlated with the stack height $(\mathrm{Lc})$ of the activated carbon.
\end{abstract}

Keyword: Terminalia Catappa Shell, Potassium Hydroxide, Microwave Irradiation, Activated Carbon, Surface Area.

Received 20 December 2018 | Revised [12 February 2019] | Accepted [28 February 2019]

\section{Introduction}

The awareness towards environmental protection has drawn attention and focus since a few decades ago. The rapid movement of technology and waste producing industries are foreseen to threat the public health and environment in the absence of proper management. For this cause, the activated carbon have been proved to be the effective absorber to remove the organic and inorganic pollutants, either for those dissolved in the water or formed by the environmental gas.

The activated carbon is known to contain fine pore structure, with micropores to macropores size, reaching $2585 \mathrm{~m}^{2} / \mathrm{g}$ in width for its internal surface area. It also show thermal stability and low reactivity towards acid / base [1]. With the quality of its pore structure, the activated carbon has been applied regularly in industrial field, especially in gas refinery technology [2], the removal of organic pollutants [3], food processing [4], chemical and pharmaceutical industries [5], waste management (coloring substances, metals, detergent, herbicides, pesticides and

*Corresponding author at: Bina Widya Km 12.5 Simpang Baru Pekanbaru, 28293

E-mail address: awitdrus@lecturer.unri.ac.id 
policyclic aromatic hydrocarbon [6] and [7], smell and taste [8], and supercapacitor electrode [9] and [10].

However, the activated carbon on the market usually costs relatively high due to the unrenewable resources and the expensive raw materials it uses, such as coal [11]. The activated carbon composed by biomass makes a suitable absorbent material because of its economic price, the large amount of availability, and its renewable nature. Some types of biomass being examined as the basic materials of activated carbon include Albizia lebbeck [12], cotton stems [13], tobacco stems [14], pineapple skin [3] and the fiber of palm bunches [9] and [10]. It takes generally two steps to produce activated carbon, firstly by carbonization (heating on 500 $800^{\circ} \mathrm{C}$ overflowed by $\mathrm{N}_{2}$ ) and secondly by carbon activation. Carbon activation is divided into two, which are the chemical activation (heating on $600-800^{\circ} \mathrm{C}$ overflowed by $\mathrm{N}_{2}$ ) and physical / thermal (heating on $800-1000^{\circ} \mathrm{C}$ overflowed by $\mathrm{CO}_{2}$ or vapor) [9] and [15]. However the process above requires long duration, high amount of energy and gas, which leads to high expenses.

In this study, the carbon activation from Terminalia catappa shells uses the chemical activation assisted by microwave heating. The use of microwave heating will show some unique superiorities, i.e the high energy efficiency, high heating speed, the outward volumetric heating, the diverse heating [16] and the relatively short time for the heating process [12]. This will cause the decrease in energy consumption and hence, the costs. On the other hand, the gas consumption in the activated carbon production can be reduced. This chemical activation inducted from microwave heating can be used as one way to solve the problems in producing activated carbon.

\section{Materials and Methods}

The biomass material as activated carbon was the Terminalia catappa shells, grew in the area around Universitas Riau. The pre-carbonization of Terminalia catappa shells was done using an oven, processed at the temperature of $200^{\circ} \mathrm{C}$ for 3 hours. The pre-carbonized shells were mashed and sifted to particles of $149 \mu \mathrm{m}$ in size.

The chemical activation of the pre-carbonized Terminalia catappa shells was conducted in 24 hours on room temperature. The comparison of $\mathrm{KOH}$ on the pre-carbonized Terminalia catappa shells were: 4:1, 4:2 and 4:3 each in 150ml distilled water.

The microwave irradiation towards sample was done on 630 Watt for 20 minutes using the Sharp R728(S)-IN microwave oven. The activated carbon was repeatedly cleaned to $\mathrm{pH} 7$ and dried at the temperature of $100^{\circ} \mathrm{C}$ for 24 hours. The characterization towards sample involved the micro structure, using X-Ray Diffraction, surface morphology and X-Ray dispersive energy, 
while surface area was using $\mathrm{N}_{2}$ adsorption-desorption isotherm at the temperature of $77 \mathrm{~K}$ and the absorption test towards methylene blue.

\section{Result and Discussion}

The pattern of X-ray diffraction is shown on Figure 1. This pattern indicates the typical activated carbon from biomass, which consists of two peaks: peak (002) on $2 \theta \sim 22^{\circ}$ point and peak (100) on $2 \theta \sim 42^{\circ}$ point. The microstructure of activated carbon which consists of distance between planes $\left(\mathrm{d}_{002}\right.$ and $\left.\mathrm{d}_{100}\right)$ was calculated by the Bragg's equation $n \lambda=2 \mathrm{~d} \sin \theta$ while microcrystalline dimension (stack height $\mathrm{L}_{c}$ and stack width $\mathrm{L}_{\mathrm{a}}$ ) was calculated using the Scherrer equation $L_{c, a}=\frac{K \lambda}{\beta_{c, a} \cos \theta}$ where $\mathrm{K}$ is the shape factor matching with 0.89 for $\mathrm{L}_{\mathrm{c}}$ and 1.84 for $L_{a}$ and $\beta$ is the width of the peak on half maximum [17]. Distance between planes and microcrystalline dimension are indicated in table 1.

The mass comparison between pre-carbonized activated carbon and $\mathrm{KOH}$ did not inflict any significant impacts towards the distance between planes, both for distance between planes $\mathrm{d}_{002}$ and $\mathrm{d}_{100}$, as seen in table 1 . This indicates that $\mathrm{KOH}$ did not affect the distance between planes $\mathrm{d}_{\mathrm{hkl}}$. This result was also correlated to the result from Farma et al [18], but with lower value of $\mathrm{d}_{002}$. The chemical activation assisted by microwave irradiation was mainly about creating pores, expanding the pores and activating carbon. This was indicated by stack height $\mathrm{L}_{\mathrm{c}}$. According to Lee and Pyun [19] and Boyea et al. [20], the higher the value of $L_{c}$, the wider of surface can be formed.

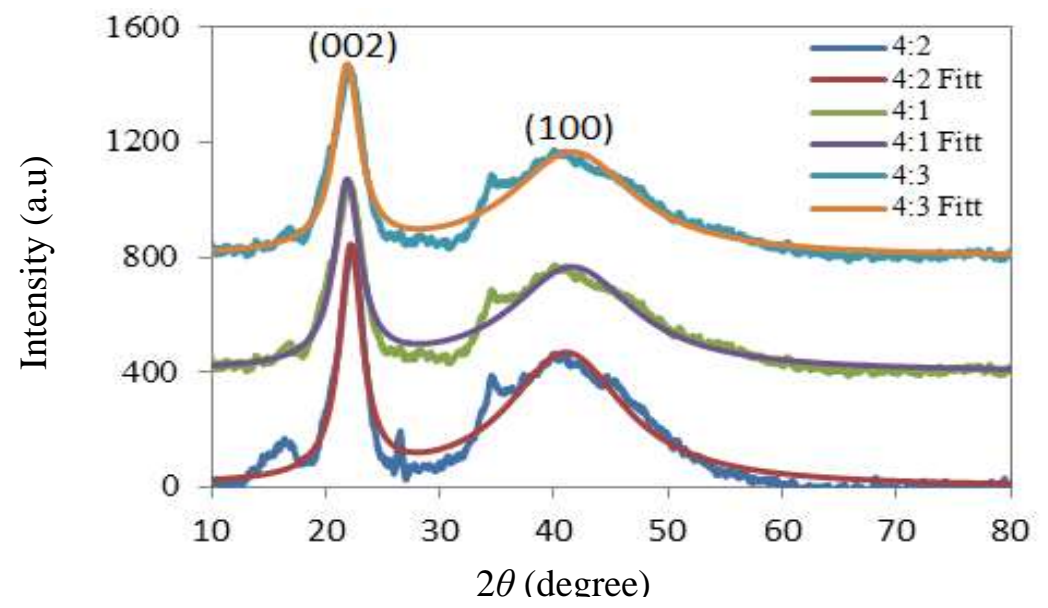

Figure 1. X-Ray Difraction Pattern

The comparison of the activated micro carbon is indicated in Figure 2. The picture of micro was obtained from the electron scanning microscope with 1000x enlargement. The micro picture (c) is seen to be more porous than micro (a) and (b) which is caused by $\mathrm{KOH}$ activity. 
Figure 3 shows $\mathrm{N}_{2}$ isotherm absorption at the temperature of $77 \mathrm{~K}$ for sample KA41 and KA43.

The two adsorption-desorption isotherms showed similarly type I pattern according to IUPAC standard [21]. Type I indicates that the pores formed in activated carbon were mainly micropores, which was seen by the increase of adsorption volume on relative pressure $0-0.1$ also small part of mesopores seen from the stable adsorption-desorption volume on relative pressure $0.1-0.9$. When pressure was higher than 0.9 , the volume would drastically increase, indicating the occurrence of adsorption-desorption on macropores. The micropores and mesopores formed in activated carbon were highly dependent on the comparison between carbon and $\mathrm{KOH}$, where higher $\mathrm{KOH}$ on chemical activation will transform micropores to mesopores. Micropores and mesopores hold important roles in activated carbon, both as absorber and electrode because they perform different orders on the transfer rate and doublelayer formation on the surface of activated carbon.

Table 1. Distance between planes and the microcrystalline dimension of activated carbon

\begin{tabular}{ccccc}
\hline \multirow{2}{*}{ Sample } & \multicolumn{2}{c}{ Distance between planes $(\mathrm{nm})$} & \multicolumn{2}{c}{$\begin{array}{c}\text { Microcrystalline Dimension } \\
(\mathrm{nm})\end{array}$} \\
\cline { 2 - 5 } & $\mathrm{d}_{002}$ & $\mathrm{~d}_{100}$ & $\mathrm{~L}_{\mathrm{c}}$ & $\mathrm{L}_{\mathrm{a}}$ \\
\hline KA41 & 0.4064 & 0.2151 & 3.0273 & 1.2347 \\
KA42 & 0.3999 & 0.2197 & 3.6639 & 1.2349 \\
KA43 & 0.4002 & 0.2196 & 3.7836 & 1.1964 \\
\hline
\end{tabular}

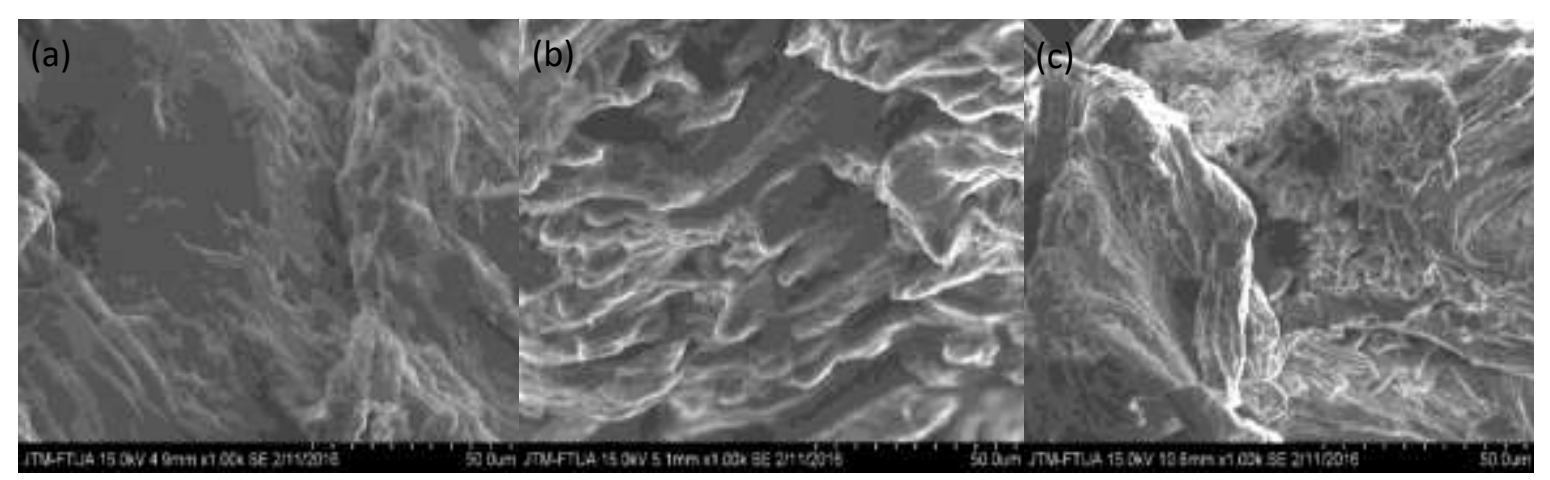

Figure 2. The picture of activated micro carbon (a) KA41, (b). KA42 and (c) KA43

The width of surface was determined by data analysis of $\mathrm{N}_{2}$ adsorption-desorption isotherm at at the temperature of $77 \mathrm{~K}$ by using BET equality. The quantitative analysis on isotherm data showed that the width and the approximate pores diametre on BET surface were reaching 289 $\mathrm{m}^{2} / \mathrm{g}$ and $3.0379 \mathrm{~nm}$, and $312 \mathrm{~m}^{2} / \mathrm{g}$ and $3.0392 \mathrm{~nm}$ each for sample KA41 dan KA43.

The quality of activated carbon as an absorber was determined by the absorption of activated carbon towards methylene blue. The absorption rate for sample KA41, KA42 and KA43 can be seen in Figure 4. The highest absorption rate towards methylene blue is seen in sample KA43 with $84.383 \mathrm{mg} / \mathrm{g}$. This absorption rate was correlated to the study of BET surface area and stack height $\mathrm{L}_{\mathrm{c}}$. All samples of activated carbon met the standards of Indonesia's Industial Standard Classification / Standar Industri Indonesia (SII) No. 0258-59 because the absorption rate towards methylene blue was higher than $60 \mathrm{mg} / \mathrm{g}$. 


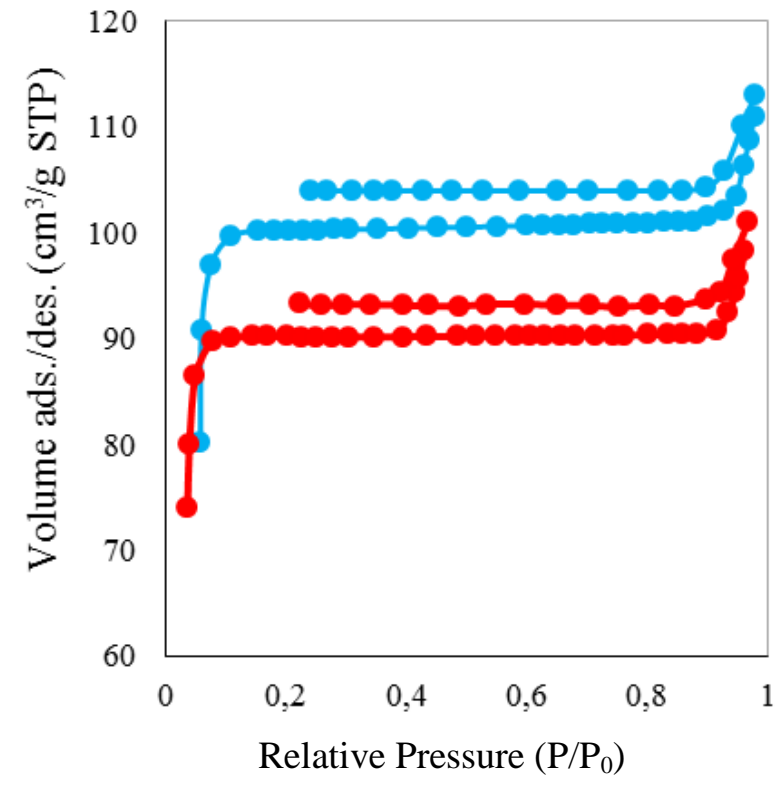

Figure 3. $\mathrm{N}_{2}$ adsorption-desorption isotherm at $77 \mathrm{~K}$ for sample KA41 and KA43

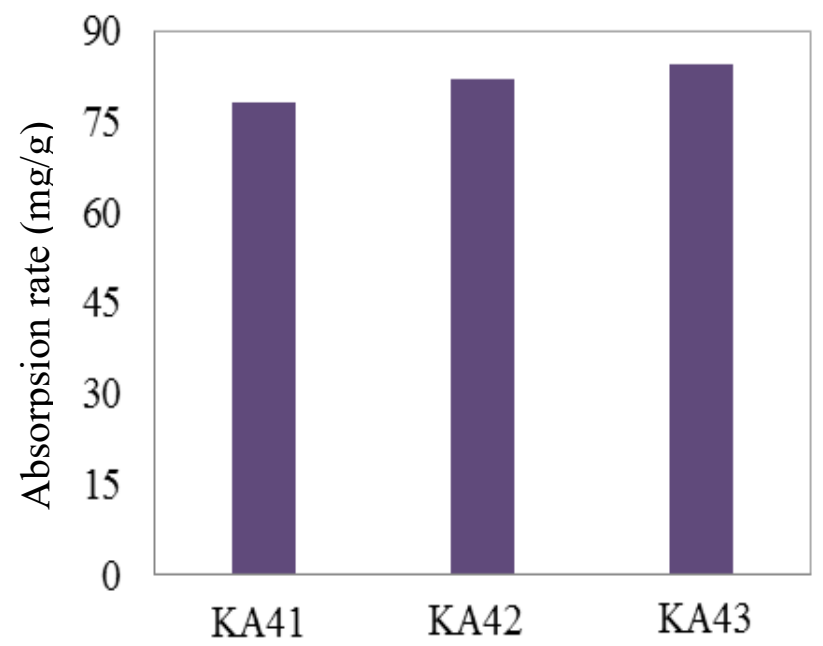

Figure 4. The absorption rate of activated carbon towards methylene blue

\section{Conclusion}

The Terminalia catappa shell based activated carbon was produced by microwave asissted $\mathrm{KOH}$ activation. The activated carbon obtained by the comparison of pre-carbonized Terminalia catappa shells and $\mathrm{KOH} \mathrm{4:3} \mathrm{(KA43)} \mathrm{are} \mathrm{the} \mathrm{best} \mathrm{activated} \mathrm{carbon.} \mathrm{This} \mathrm{result} \mathrm{was} \mathrm{supported} \mathrm{by}$ stack height $\mathrm{L}_{\mathrm{c}}$ and BET surface area. The absorption rate of activated carbon towards methylene blue for all samples passed the minimum standard of Indonesia's Industial Standard Classification / Standard Industri Indonesia. Sample KA43 was supported by stack height $\mathrm{L}_{\mathrm{c}}$, BET surface area and absorption rate towards methylene blue by $3.7836 \mathrm{~nm}, 312 \mathrm{~m}^{2} / \mathrm{g}$ and $84.383 \mathrm{mg} / \mathrm{g}$, respectively. 


\section{Acknowledgement}

To The Mnistry of Research, Technology and Higher Education of the Republic of Indonesia, and Universitas Riau for the financial funding via Penelitian Hibah Bersaing by contract number 460/UN.19.5.1.3/LT/2016.

\section{REFERENCES}

[1] X. Li, W. Xing, S. Zhuo, J. Zhou, F. Li, S. Z. Qiao and G. Q. Lu, "Preparation of Capacitor's Electrode from Sunflower Seed Shell," Bioresource Technology, vol. 102, p. 1118-1123, 2011.

[2] C. Phalakornkule, J. Foungchuen and T. Pitakchon, "Impregnation of Chitosan onto Activated Carbon for High Adsorption Selectivity towards $\mathrm{CO}_{2}: \mathrm{CO}_{2}$ Capture from Biohydrogen, Biogas and Flue Gas," Journal of Sustainable Energy \& Environment, vol. 3, pp. 153-157, 2012.

[3] K. Y. Foo and B. H. Hameed, "Porous Structure and Adsorptive Properties of Pineapple Peel Based Activated Carbons Prepared Via Microwave Assisted $\mathrm{KOH}$ and $\mathrm{K}_{2} \mathrm{CO}_{3}$ Activation," Microporous and Mesoporous Materials, vol. 148, p. 191-195, 2012.

[4] H. L. Mudogo, H. Yucel and N. S. Kincal, "Decolorization of Sugar Syrups Using Commercial and Sugar Beet Pulp Based Activated Carbons," Bioresource Technology, vol. 99, pp. 3528-3533, 2008.

[5] Z. Yu, S. Peldszus and P. M. Huck, "Adsorption Characteristics of Selected Pharmaceuticals and an Endocrine Disrupting Compound-Naproxen, Carbamazepine and Nonylphenol on Activated Carbon," Water Research, vol. 42, p. 2873-2882, 2008.

[6] G. Crini, "Non-conventional Low-cost Adsorbents for Dye Removal: a Review," Bioresource Technology, vol. 97, pp. 1061-1085, 2006.

[7] B. H. Hameed and F. B. M. Daud, "Adsorption Studies of Basic Dye on Activated Carbon Derived from Agricultural Waste: Hevea Brasiliensis Seed Coat," Chemical Engineering Journal, vol. 139, pp. 48-55, 2008.

[8] Y. I. Kim and B. U. Bae, "Design and Evaluation of Hydraulic Baffled-channel PAC Contactor for Taste and Odor Removal from Drinking Water Supplies," Water Research, vol. 41, pp. 2256-2264, 2007.

[9] Awitdrus, M. Deraman, I. A. Talib, R. Farma, R. Omar, M. M. Ishak, N. H. Basri and B. N. M. Dolah, "Effect of Compression Pressure on the Physical and Electrochemical Properties of Activated Carbon Monoliths Electrodes for Supercapacitor Application," Advanced Materials Research, vol. 501, pp. 13-18, 2012.

[10] R. Farma, M. Deraman , Awitdrus, I. A. Talib, E. Taer, N. H. Basri, J. G. Manjunatha, M. M. Ishak, B. N. M. Dollah and S. A. Hashmi, "Preparation of Highly Porous Binderless Activated Carbon Electrodes from Fibres of Oil Palm Empty Fruit Bunches for Application in Supercapacitors," application in supercapacitors, Bioresource Technology, vol. 132, pp. 254-261, 2013.

[11] A. Khelifi, M. C. Almazan-almazan, M. Perez-Mendoza, Domingo-Garcia and A. Addoun, "Influence of Nitric Acid Concentration on the Characteristics of Active Carbons Obtained from a Mineral Coal," Fuel Processing Technology, vol. 91, pp. 1338-1344, 2012.

[12] M. J. Ahmed and S. K. Theydan, "Optimization of Microwave Preparation Conditions for Activated Carbon from Albizia Lebbeck Seed Pods for Methylene Blue Dye Adsorption," Journal of Analytical and Applied Pyrolysis, vol. 105, p. 199-208, 2014.

[13] H. Deng, L. Yang, G. Tao and J. Dai, "Preparation and Characterization of Avtivated Carbon from Cotton Stalk by Microwave Assisted Chemical Activation-Application in Methylene Blue Adsorption from Aqueous Solution," Journal of Hazardous Materials, vol. 166, pp. 1514-1521, 2009.

[14] Y. Li and W. Yang, "Microwave Synthesis of Zeolite Membranes: a Review,", Journal of Membrane Science, vol. 316, pp. 3-17, 2008. 
[15] Awitdrus, M. Deraman, I. A. Talib, R. Farma, R. Omar, M. M. Ishak, E. Taer, B. N. M. Dolah, N. H. Basri and N. S. M. Noor, "Physical and Electrochemical Properties of Supercapacitor Composite Electrodes Prepared from Biomass Carbon and Carbon from Green Petroleum Coke," in AIP Conference Proceedings, 2015.

[16] H. Chen and Z. Hashisho, "Fast Preparation of Activated Carbon from Oil Sands Coke Using Microwave-assisted Activation," Fuel, vol. 95, p. 178-182, 2012.

[17] Awitdrus, M. Deraman, I. A. Talib, R. Omar, H. Jumali, E. Taer and M. M. Saman, "Microcrystallite Dimension and Total Active Surface Area of Carbon Electrode from Mixtures of Pre-carbonized Oil Palm Empty Fruit Bunches and Green Petroleum Cokes," Sains Malaysiana, vol. 39, pp. 83-86, 2010.

[18] R. Farma, M. Deraman, R. Omar, Awitdrus, M. M. Ishak, E. Taer and I. A. Talib, "Binderless Composite Electrode Monolith from Carbon Nanotube and Biomass Activated Carbon by $\mathrm{KOH}$ and $\mathrm{CO}_{2}$ Gas for Supercapacitor," in AIP Proceeding Conference, 2011.

[19] G. J. Lee and S. I. Pyun, "Effect of Microcrystallite Structures on Electrochemical Characteristics of Mesopores Carbon for Electric Double-layer Capacitors," Electrochimica Acta, vol. 51, pp. 3029-3038, 2006.

[20] J. M. Boyea, S. P. Camacho and W. J. Ready, "Carbon Nanotubes-Based Supercapacitor," Technologies and markets, vol. 4, pp. 585-593, 2007.

[21] K. S. Sing, D. H. Everett, R. H. Haul, L. Moscou, R. A. Pierotti, J. Rouquerol and T. Siemieniewski, "Reporting Physisorption Data for Gas/solid Systems with Special Reference to the Determination of Surface Area and Porosity,," Pure Applied Chemistry, vol. 57, pp. 603-619, 1985. 